\title{
Minimally invasive mitral valve repair for anterior leaflet prolapse
}

\author{
Bettina Pfannmüller, MD, Joerg Seeburger, MD, Martin Misfeld, MD, PhD, \\ Michael Andrew Borger, MD, PhD, Jens Garbade, MD, PhD, and Friedrich W. Mohr, MD, PhD
}

Objective: Mitral valve repair for anterior mitral leaflet prolapse is technically challenging. We report here our experience with minimally invasive anterior mitral leaflet repair.

\begin{abstract}
Methods: Our institutional database for minimally invasive mitral valve surgery was screened for patients with mitral regurgitation caused by isolated prolapse of the anterior mitral leaflet. Patient characteristics, intraoperative data, and short- and long-term outcomes are analyzed and reported.

Results: A total of 180 patients presented with mitral regurgitation caused by isolated anterior mitral leaflet prolapse. All patients underwent minimally invasive surgery at our institution between 1999 and 2010. Mitral valve repair was performed in 170 cases $(94.4 \%)$, and these patients form the focus of this study. The mean age of the patients was $59.7 \pm 14.8$, and their mean $\log$ EuroSCORE was $4.9 \pm 5.1$. Mean aortic crossclamp time (cardiopulmonary bypass time) was $82 \pm 25$ minutes ( $130 \pm 40$ minutes). Mitral valve repair techniques were neochordal replacement with the loop technique in $68.2 \%$ of patients, chordal transfer in $14.7 \%$, anterior mitral leaflet resection in $7.1 \%$, and edge-to-edge repair in $5.9 \%$. Thirty-day mortality was $1.8 \%$. Kaplan-Meier estimates showed $86.7 \% \pm 3.2 \%$ survival and $95.7 \% \pm 1.6 \%$ freedom from mitral valve reoperation at 5 years.
\end{abstract}

Conclusions: This large series demonstrates good results for anterior mitral leaflet repair with the minimally invasive approach. (J Thorac Cardiovasc Surg 2013;146:109-13)

Mitral valve (MV) repair for anterior mitral leaflet (AML) prolapse is technically challenging. Several repair strategies are available; however, leaflet resection and implantation of neochordae are reported to be of especial value..$^{1-5}$ Nevertheless, these repair techniques are not exclusive, and a large variety of repair techniques have proved to have acceptable long-term results. ${ }^{6-15}$

Our institutional policy for MV repair in cases of AML prolapse is to use chordal replacement by the loop technique through a minimally invasive approach. ${ }^{12,16}$ We report here on the repair strategies and long-term outcomes in patients with isolated AML prolapse undergoing minimally invasive MV surgery.

\section{MATERIALS AND METHODS}

Between September 1999 and May 2010, a total of 180 patients underwent surgery for isolated AML prolapse at our institution through a minimally invasive technique. Indication for MV surgery was moderate or severe mitral regurgitation (MR) as a result of AML prolapse, with either symptoms of heart failure, signs of left ventricular dysfunction, or dilation of the left ventricle. Patients with prolapse of the posterior mitral leaflet, those with previous cardiac surgery, and those undergoing concomitant tricuspid valve surgery were excluded from this study.

\footnotetext{
From the Department of Cardiac Surgery, University of Leipzig Heart Center, Leipzig, Germany.

Disclosures: Authors have nothing to disclose with regard to commercial support.

Received for publication Jan 29, 2012; revisions received May 4, 2012; accepted for publication June 15, 2012; available ahead of print July 16, 2012.

Address for reprints: Bettina Pfannmüller, MD, University of Leipzig-Heart Center,

Department of Cardiac Surgery, Strümpellstrasse 39, 04289, Leipzig, Germany

(E-mail: pfab@med.uni-leipzig.de).

$0022-5223 / \$ 36.00$

Copyright (c) 2013 by The American Association for Thoracic Surgery

http://dx.doi.org/10.1016/j.jtcvs.2012.06.044
}

MV repair was successfully performed in 170 patients $(94.4 \%)$, and these form the focus of this study. In the remaining 10 patients $(5.9 \%)$, MV replacement was necessary, in 1 case after a failed repair with good postoperative outcome. Predominant MV pathologies according to MV repair versus replacement are depicted in Figure 1. MV replacement was indicated in patients with significant sclerosis of the MV annulus and leaflets, whereas annular dilatation was present in most patients who underwent MV repair.

The study was approved by the local ethics committee, Preoperative, intraoperative, and postoperative characteristics of patients were prospectively entered into our institutional database and retrospectively analyzed. In addition, preoperative and predischarge echocardiographic reports were collected and analyzed. MR was calculated by measurement of vena contracta $(\mathrm{VC})$ in a 4-chamber view. ${ }^{17}$ The MR grading was defined as follows: none ( $\mathrm{VC}$ of 0 ), mild ( $\mathrm{VC}<3 \mathrm{~mm}$ ), moderate ( $\mathrm{VC}$ of 3-6.9 mm), and severe $(\mathrm{VC} \geq 7 \mathrm{~mm}) .{ }^{18}$

\section{Surgical Technique}

MV surgery was performed through a 5- to 8-cm right anterolateral minithoracotomy in the 4th or 5th intercostal space, as previously described elsewhere. ${ }^{12,14,19}$ The Chitwood clamp was used for aortic occlusion. ${ }^{20}$ Transesophageal echocardiography was routinely performed for assessment of MV anatomy and function and for evaluation of left ventricular function before and after MV repair.

All but 2 patients $(1.2 \%)$ received a MV ring annuloplasty with either a complete rigid ring $(90.0 \% ; \mathrm{n}=153)$ or an incomplete flexible band $(8.8 \% ; \mathrm{n}=15)$.

The technique chosen to correct the AML prolapse was at the surgeon's discretion. Most patients $(\mathrm{n}=116 ; 68.2 \%)$ underwent implantation of neochordae by the loop technique, which has been well described elsewhere. $^{15,16}$

\section{Follow-up}

Individual patient contact after discharge was performed by sending questionnaires to all patients annually. Patients who did not respond were contacted by phone call. In case no further information was available, family physicians were contacted. Follow-up was $94 \%$ complete, with a mean follow-up time of $4.3 \pm 2.9$ years (range, 1 day-11.8 years). 


\section{Abbreviations and Acronyms \\ $\mathrm{AML}=$ anterior mitral leaflet \\ $\mathrm{CI}=$ confidence interval \\ $\mathrm{MR}=$ mitral regurgitation \\ $\mathrm{MV}=$ mitral valve \\ $\mathrm{VC}=$ vena contracta}

(44/143), and as moderate in 3.6\% (5/143). In 141 patients $(83 \%)$, preoperative and predischarge echocardiographic imaging was available for a correlation, which is shown in Figure 3. There was no significant difference in predischarge MR grading between patients undergoing repair with versus without the loop technique $(P=.5)$.

Eleven patients required late reoperation, 8 for MVrelated causes. Reason for MV-related reoperation was recurrent MR in 6 patients: in 4 of these patients as a result of ring dehiscence, in 1 patient because of occlusion of the circumflex artery, and in 1 patient because of injury of the aortic valve from MV suture placement. Reoperations for causes not related to the MV occurred in 3 cases: 2 patients underwent subsequent heart transplant, and 1 underwent isolated tricuspid valve repair. Freedom from MV-related reoperation at 5 years was $95.7 \% \pm 1.9 \%$ (95\% confidence interval [CI] for mean survival time/ mean time of freedom from reoperation, 126.9-138.7 months; Figure 4).

Overall 30-day mortality was $1.8 \%$ (3 patients). One patient died of acute aortic dissection 6 days after surgery and an initially uneventful postoperative course. One patient had acute lung failure develop, and the remaining patient died of low-output postcardiotomy syndrome (preoperative left ventricular ejection fraction, $15 \%$ ).

There were 15 late deaths. Reasons for death were carcinoma in 2 patients (63 and 64 years old), gastrointestinal bleeding in 1 patient (79 years old), pneumonia with sepsis in 1 patient (41 years old), cardiac-related cause in 1 patient (preoperative left ventricular ejection fraction 15\%, 49 years old), and unknown in 10 patients.

Overall 5-year survival was $88.2 \% \pm 3.0 \%(95 \% \mathrm{CI}$, 115.0-130.7 months). There was no survival difference at 5 years with respect to the use of the loop technique, with a survival of $88.8 \% \pm 3.8 \%(95 \%$ CI, $106.0-135.7$ months) with the technique versus $83.8 \% \pm 5.7 \%(95 \%$ CI, 107.5-131.6 months) without it (Figure 5).

\section{DISCUSSION}

In this study, we have demonstrated the feasibility and safety of MV repair of AML prolapse through a minimally invasive technique. A high freedom from MV-related reoperation was achieved.

Several investigators have demonstrated the value of polytetrafluoroethylene sutures for chordal replacement in the treatment of AML prolapse, with promising longterm results. Frater and colleagues ${ }^{4}$ initiated the use of polytetrafluoroethylene sutures for chordal replacement in 1983. This approach was taken up and modified by David and colleagues, ${ }^{1}$ who reported their initial experience with polytetrafluoroethylene chordal replacement in 1989. The latter group later demonstrated an excellent 10-year freedom from MV-related reoperation of $96 \% \pm 1 \%$ among patients with myxomatous disease with and without 


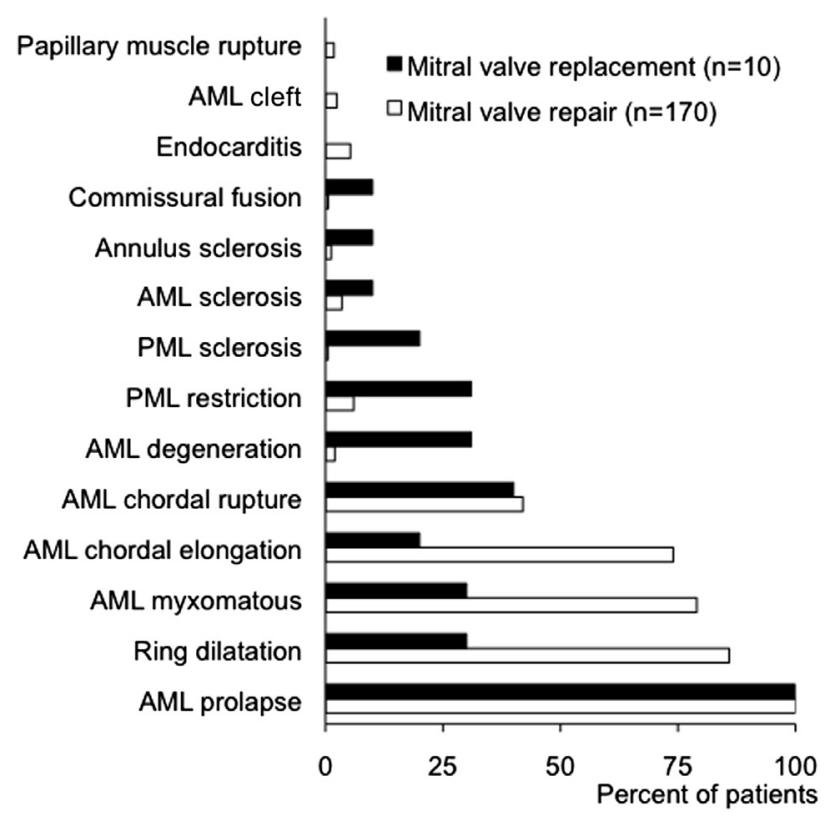

FIGURE 1. Mitral valve pathology in patients undergoing mitral valve repair or replacement. $A M L$, Anterior mitral leaflet; $P M L$, posterior mitral leaflet.

polytetrafluoroethylene chordal replacement and concluded that polytetrafluoroethylene chordal replacement was associated with no observable adverse effects on the probability of MV repair success. ${ }^{21}$ In 2005, the same group reported a freedom from severe recurrent MR rate of $86 \%$ at 12 years after MV repair for AML prolapse and an $88 \% \pm 4 \%$ freedom from MV-related reoperation. ${ }^{7}$ Approximately three quarters of these patients were treated with polytetrafluoroethylene chordal replacement, results that highlight the value of the chordal replacement concept. $^{7}$

Kasegawa and associates ${ }^{11}$ reported similar results, with a 12-year freedom from severe recurrent MR of $88 \% \pm 3 \%$ and a $90 \% \pm 3 \%$ freedom from MV-related reoperation after repair for AML prolapse. The vast majority of their

TABLE 1. Demographic data of all patients undergoing minimally invasive mitral valve repair for anterior leaflet prolapse $(n=170)$

\begin{tabular}{lc}
\hline Age (y, mean \pm SD) & $59.7 \pm 14.8$ \\
Male (no.) & $97(57.1 \%)$ \\
Preoperative NYHA functional class (mean \pm SD) & $2.3 \pm 0.9$ \\
Logistic EuroSCORE (mean \pm SD) & $4.9 \% \pm 5.1 \%$ \\
Left ventricular ejection fraction $(\%$, mean \pm SD) & $61.2 \% \pm 11.9 \%$ \\
Mean pulmonary arterial pressure (mm Hg, & $26.4 \pm 19.5$ \\
$\quad$ mean \pm SD) & \\
Atrial fibrillation (no.) & $57(33.5 \%)$ \\
Hypertension (no.) & $94(55.3 \%)$ \\
Diabetes mellitus (no.) & $16(9.4 \%)$ \\
Permanent pacemaker or AICD (no.) & $13(7.7 \%)$ \\
\hline AICD, Automatic implantable cardioverter/defibrillator; NYHA, New York Heart \\
Association.
\end{tabular}

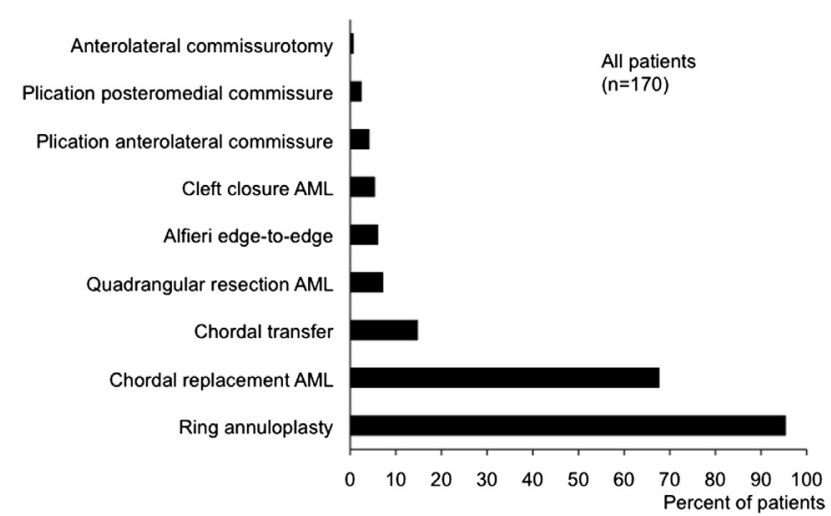

FIGURE 2. Methods of mitral valve repair. $A M L$, Anterior mitral leaflet.

patients $(93 \%)$ were treated with polytetrafluoroethylene sutures. Although these studies included patients undergoing MV repair through a median sternotomy, Rodriguez and coworkers ${ }^{13}$ showed a $91 \%$ 3-year freedom from MV-related reoperation after robotic MV repair for AML prolapse. This is of especial note because it proves the adaptability of chordal replacement to the use of an intraoperative telemanipulator.

Alternative concepts to chordal replacement, however, do exist. Long-term results after MV repair of AML prolapse with the edge-to-edge repair and chordal transfer are promising as well. De Bonis and colleagues ${ }^{8}$ reported a $96.6 \% \pm 1.7 \% 5$-year freedom from reoperation rate for patients treated with a surgical edge-to-edge repair technique for AML prolapse. This is similar to the experience of the Cleveland clinic with chordal transfer, reported in 2004 by Gillinov and colleagues ${ }^{10}$ : they had a 5 -year freedom from reoperation after MV repair for AML prolapse of $96 \%$.

TABLE 2. Length and number of implanted polytetrafluoroethylene loops for chordal replacement

\begin{tabular}{lcccr}
\hline & No. of loops & $\begin{array}{c}\boldsymbol{P} \\
\text { value }\end{array}$ & $\begin{array}{c}\text { Loop length } \\
(\mathbf{m m})\end{array}$ & $\begin{array}{c}\boldsymbol{P} \\
\text { value }\end{array}$ \\
\hline A1 segment & & & & \\
$\quad$ All patients $(\mathrm{n}=28)$ & $1.9 \pm 1.0$ & & $22.0 \pm 3.0$ & \\
$\quad$ Sex & & .04 & & .02 \\
$\quad$ Male $(\mathrm{n}=23)$ & $2.0 \pm 1.1$ & & $22.6 \pm 2.5$ & \\
$\quad$ Female $(\mathrm{n}=5)$ & $1.0 \pm 0.0$ & & $19.2 \pm 3.6$ & \\
A2 segment & & & & \\
$\quad$ All patients $(\mathrm{n}=108)$ & $3.0 \pm 1.2$ & & $21.0 \pm 3.3$ & \\
$\quad$ Sex & & .6 & & $<.01$ \\
$\quad$ Male $(\mathrm{n}=60)$ & $3.1 \pm 1.3$ & & $22.0 \pm 3.2$ & \\
$\quad$ Female (n=48) & $2.9 \pm 1.0$ & & $20.3 \pm 3.3$ & \\
A3 segment & & & & \\
$\quad$ All patients (n=51) & $1.7 \pm 0.9$ & & $21.6 \pm 3.1$ & \\
Sex & & .5 & & $<.01$ \\
$\quad$ Male $(\mathrm{n}=35)$ & $1.8 \pm 0.9$ & & $22.4 \pm 2.9$ & \\
$\quad$ Female (n=21) & $1.6 \pm 1.0$ & & $20.11 \pm 2.9$ & \\
\hline
\end{tabular}

Data are mean \pm SD. 


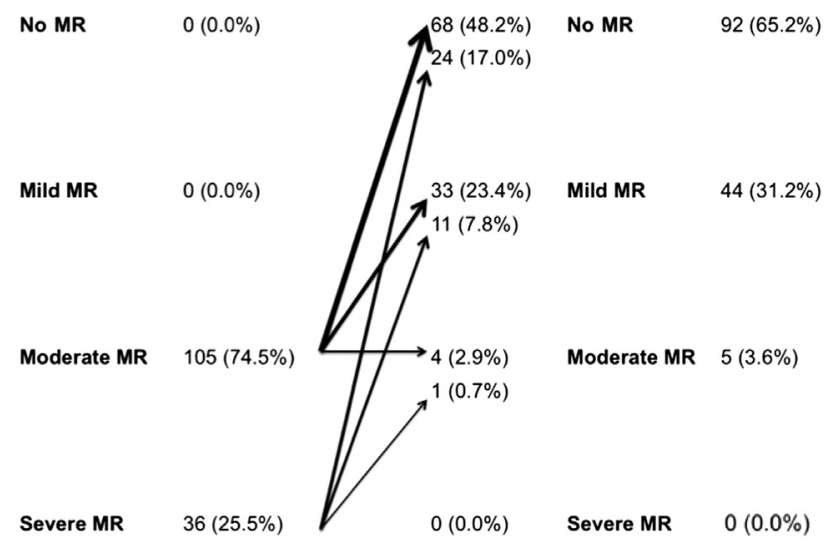

FIGURE 3. Correlation between preoperative and predischarge echocardiographic studies. $M R$, Mitral regurgitation.

In contrast, chordal shortening is associated with worse long-term results than either chordal replacement or edge-to-edge repair. Phillips and coworkers ${ }^{22}$ published a $98.6 \%$ freedom from reoperation at 3.5 postoperative years after chordal replacement versus $85.2 \%$ after chordal shortening. Smedira and associates ${ }^{23}$ reported a 5-year freedom from reoperation of $90 \%$ to $96 \%$ after chordal transfer, compared with only $74 \%$ after chordal shortening.

Although repair of AML prolapse is traditionally considered to be more technically complex than repair of isolated posterior mitral leaflet prolapse, our results confirm that patients with AML prolapse can be successfully treated with

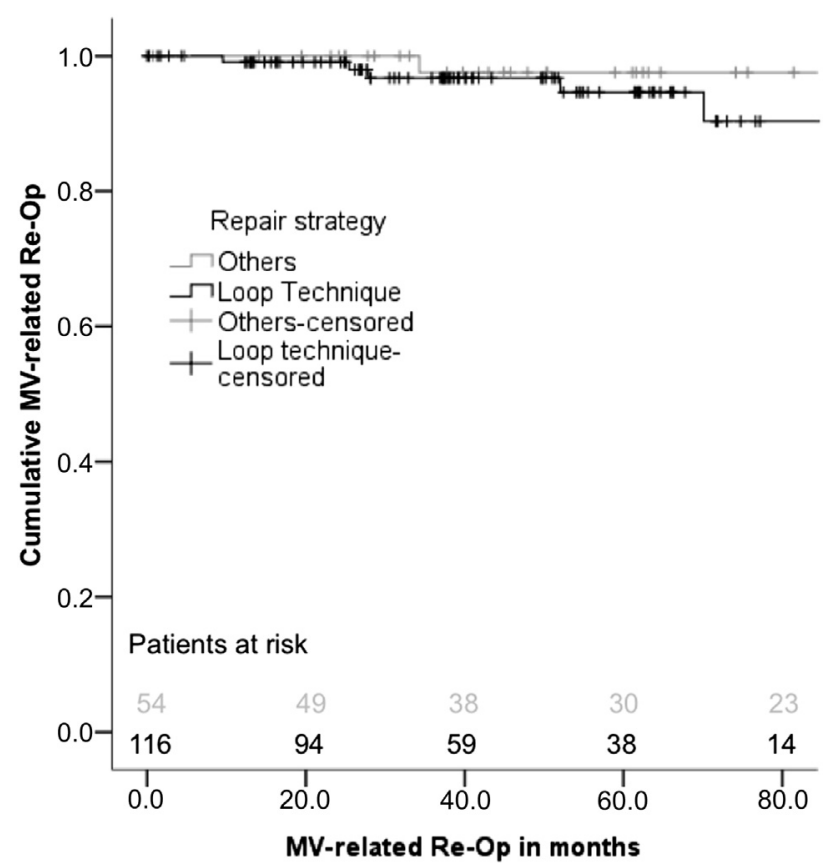

FIGURE 4. Freedom from mitral valve-related reoperation ( $M V$-related $R e-O p$ ) in patients undergoing mitral valve repair performed with or without the loop technique.

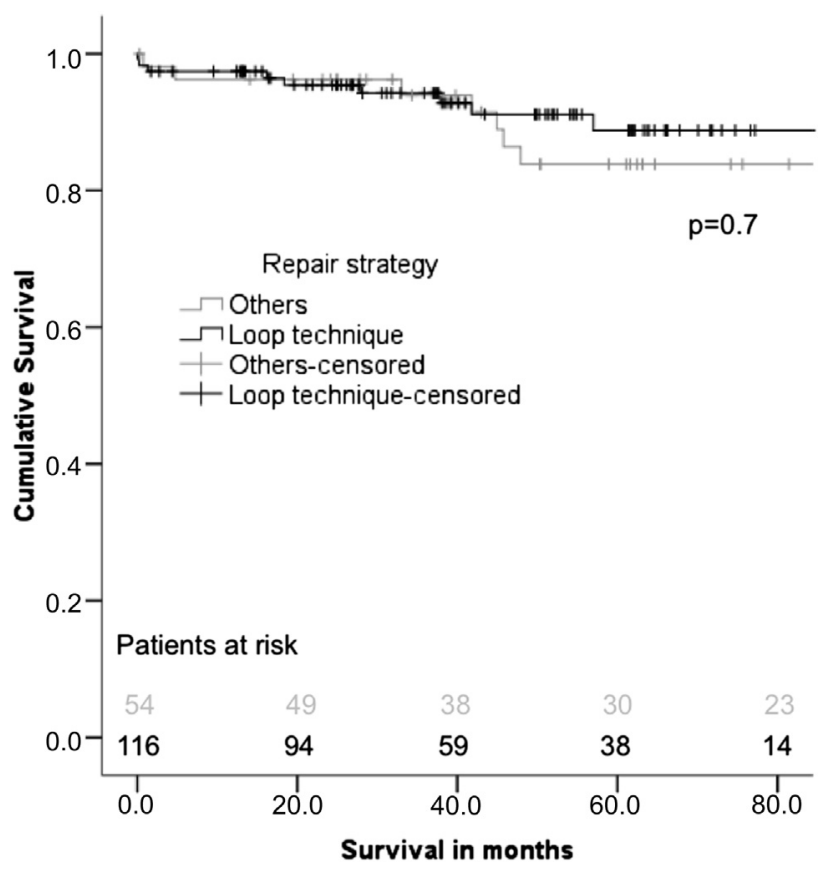

FIGURE 5. Postoperative survival of patients after mitral valve repair performed with or without the loop technique.

a minimally invasive approach and the use of neochordal implantation. As previously reported by our group, ${ }^{12,15,16}$ the premeasured loop technique is a highly reproducible and standardized method for MV repair. It was originally developed to facilitate AML prolapse repair through a minithoracotomy. Premeasured loops are available in 2 -mm increments between 10 and $26 \mathrm{~mm}$ in length. When applying this technique, the precise measurement of the loop length is among the most challenging and most important steps of the procedure. The data presented in this article offer some guidance for surgeons adopting this technique. Especially, the mean lengths of loops used in our large series may help other groups in reaching an optimal postoperative result in these sometimes challenging AML repair operations.

\section{Study Limitations}

The main limitation of this study is its retrospective nature. It does, however, represent one of the largest series to date of patients with isolated AML prolapse. We therefore believe that it is worth presenting. Another significant limitation is the lack of long-term echocardiographic follow-up data. This lack is due mainly to the fact that well over a third of our patients undergoing MV repair are referred from distant regions.

\section{CONCLUSIONS}

AML prolapse can be safely and effectively treated with minimally invasive MV repair, with good long-term results. 


\section{References}

1. David TE. Replacement of chordae tendineae with expanded polytetrafluoroethylene sutures. J Card Surg. 1989;4:286-90.

2. Carpentier A, Relland J, Deloche A, Fabiani JN, D'Allaines C, Blondeau P, et al. Conservative management of the prolapsed mitral valve. Ann Thorac Surg. 1978; 26:294-302.

3. Carpentier A. Cardiac valve surgery - the "French correction" J Thorac Cardiovasc Surg. 1983;86:323-37.

4. Frater RW, Gabbay S, Shore D, Factor S, Strom J. Reproducible replacement of elongated or ruptured mitral valve chordae. Ann Thorac Surg. 1983;35:14-28.

5. Fucci C, Sandrelli L, Pardini A, Torracca L, Ferrari M, Alfieri O. Improved results with mitral valve repair using new surgical techniques. Eur J Cardiothorac Surg. 1995;9:621-7.

6. Alfieri O, De Bonis M, Lapenna E, Regesta T, Maisano F, Torracca L, et al. "Edge-to-edge" repair for anterior mitral leaflet prolapse. Semin Thorac Cardiovasc Surg. 2004;16:182-7.

7. David TE, Ivanov J, Armstrong S, Christie D, Rakowski H. A comparison of outcomes of mitral valve repair for degenerative disease with posterior, anterior, and bileaflet prolapse. J Thorac Cardiovasc Surg. 2005;130:1242-9.

8. De Bonis M, Lorusso R, Lapenna E, Kassem S, De Cicco G, Torracca L, et al. Similar long-term results of mitral valve repair for anterior compared with posterior leaflet prolapse. J Thorac Cardiovasc Surg. 2006;131:364-70.

9. Fundaró P, Moneta A, Villa E, Pocar M, Triggiani M, Donatelli F, et al. Chordal plication and free edge remodeling for mitral anterior leaflet prolapse repair: 8-year follow-up. Ann Thorac Surg. 2001;72:1515-9.

10. Gillinov AM, Cosgrove DM. Chordal transfer for repair of anterior leaflet prolapse. Semin Thorac Cardiovasc Surg. 2004;16:169-73.

11. Kasegawa H, Shimokawa T, Shibazaki I, Hayashi H, Koyanagi T, Ida T. Mitral valve repair for anterior leaflet prolapse with expanded polytetrafluoroethylene sutures. Ann Thorac Surg. 2006;81:1625-31.

12. Kuntze T, Borger MA, Falk V, Seeburger J, Girdauskas E, Doll N, et al. Early and mid-term results of mitral valve repair using premeasured Gore-Tex loops ('loop technique'). Eur J Cardiothorac Surg. 2008;33:566-72.
13. Rodriguez E, Nifong LW, Chu MW, Wood W, Vos PW, Chitwood WR. Robotic mitral valve repair for anterior leaflet and bileaflet prolapse. Ann Thorac Surg. 2008;85:438-44.

14. Seeburger J, Borger MA, Falk V, Kuntze T, Czesla M, Walther T, et al. Minimal invasive mitral valve repair for mitral regurgitation: results of 1339 consecutive patients. Eur J Cardiothorac Surg. 2008;34:760-5.

15. Seeburger J, Kuntze T, Mohr FW. Gore-Tex chordoplasty in degenerative mitral valve repair. Semin Thorac Cardiovasc Surg. 2007;19:111-5.

16. von Oppell UO, Mohr FW. Chordal replacement for both minimally invasive and conventional mitral valve surgery using premeasured Gore-Tex loops. Ann Thorac Surg. 2000;70:2166-8.

17. Fehske W, Omran H, Manz M, Köhler J, Hagendorff A, Lüderitz B. Color-coded Doppler imaging of the vena contracta as a basis for quantification of pure mitral regurgitation. Am J Cardiol. 1994;73:268-74.

18. Zoghbi WA, Enriquez-Sarano M, Foster E, Grayburn PA, Kraft CD, Levine RA et al. Recommendations for evaluation of the severity of native valvular regurgitation with two-dimensional and Doppler echocardiography. J Am Soc Echocardiogr. 2003; 16:777-802.

19. Mohr FW, Falk V, Diegeler A, Walther T, van Son JA, Autschbach R. Minimally invasive port-access mitral valve surgery. J Thorac Cardiovasc Surg. 1998; 115(3):567-76.

20. Chitwood WR Jr, Elbeery JR, Moran JF. Minimally invasive mitral valve repair using transthoracic aortic occlusion. Ann Thorac Surg. 1997;63:1477-9.

21. David TE, Omran A, Armstrong S, Sun Z, Ivanov J. Long-term results of mitral valve repair for myxomatous disease with and without chordal replacement with expanded polytetrafluoroethylene sutures. J Thorac Cardiovasc Surg. 1998;115: 1279-86.

22. Phillips MR, Daly RC, Schaff HV, Dearani JA, Mullany CJ, Orszulak TA. Repair of anterior leaflet mitral valve prolapse: chordal replacement versus chordal shortening. Ann Thorac Surg. 2000;69:25-9.

23. Smedira NG, Selman R, Cosgrove DM, McCarthy PM, Lytle BW, Taylor PC, et al. Repair of anterior leaflet prolapse: chordal transfer is superior to chordal shortening. J Thorac Cardiovasc Surg. 1996;112:287-92. 